\title{
PROCESSED SEAWEED AND WINEMAKING WASTE CO-FERMENTATION FOR BIOGAS EXTRACTION: PILOT STUDY
}

\author{
Uldis Zaimis, Roberts Jurmalietis, Anita Jansone \\ Liepaja University, Latvia \\ uldis.zaimis@liepu.lv, roberts.jurmalietis@liepu.lv, anita.jansone@liepu.lv
}

\begin{abstract}
Marine macroalgae (seaweed) conventionally has been used for environmental and commercial purposes; recently a growing interest has been focused also on seaweed detritus as a sustainable/cost-efficient feedstock for biogas (biomethane) anaerobic production. A wide set of factors influence the yield of biogas nevertheless, the recent paper emphasizes pretreatment of processed algal material (substrate) with winemaking waste (inoculum) as a particularly promising project for biogas production. Relevant pilot study carried out at the Liepaja University clearly demonstrates advantages of such a combination (i.e. co-fermentation of mixed substances) for biofuel feedstock design: winemaking waste considerably increases biogas (biomethane) output from seaweed substrate. Still, the results of these preliminary experiments have to be supported by further research.
\end{abstract}

Keywords: processed seaweeds, winemaking waste, anaerobic digestion, biogas, substrate-inoculum.

\section{Introduction}

Rapid growth of energy consumption escalates global community's dependence on nonrenewable fossil fuel (which supplies about $80 \%$ of the world's energy needs [1]) making it more and more urgent to search for alternative, more secure energy sources.

Recently different energy types have been appraised and are already in use to replace fossil fuels - e.g. wind, solar, geothermal, tidal, nuclear, hydroelectric, biofuel, etc. energy. However, these alternative energy resources often possess specific disadvantages, like costliness, dependence on environmental conditions, damage to ecosystems, a lot of space needed (for discussion see, e.g. [2]) consequently, viability considerations are of particular importance, when deciding about alternative energy projects.

Bearing in mind this viability/sustainability approach the authors of the present paper are focusing on easy-to-access organic waste materials (namely, macroalgae detritus enhanced by winemaking waste inoculum) derived biogas as a particularly promising option within the spectrum of fossil fuel substitutions. Liepaja District (Baltic Sea coastal area in Western Latvia) has been used as a research site, where algae raw biomaterial has been collected and seaweed biofuels related experiments carried out.

\section{Macroalgae (seaweed) as a biogas source: background considerations}

Combustible biogas could be obtained through anaerobic digestion from very different biodegradable substances like food waste, sewage sludge, wastewater, livestock manure, crops and grass, seaweeds, etc. The latter - i.e. marine macroalgae (macrophytes) - nowadays attract a particularly growing interest as a resource for energy (biofuel) production $[1 ; 3 ; 4]$. As a relevant feedstock macroalgae appear to possess several advantages, the important among which are comparatively high growth rates (it means fast renewal of biomass used), ubiquitous distribution in different aquatic environments (avoiding thus use of agricultural lands for energy purposes and, accordingly, escaping food-fuel competition), easy way to collect/harvest dead algae (see, e.g. [1; 4; 5]). The latter statement, importantly, is related to the problem-reversal approach implementation for coastal communities. The point is that seaweed detritus is washed ashore and often piles up itself as a garbage on the beach and, accordingly, has been perceived as a nuisance by local municipality (according to rough estimate, because there are no concrete monitoring data in Latvia about seaweed detritus accumulated on the beaches, about 300-400 tons of algae waste material from Liepaja coast have been transported to local landfill annually) - however, this dead biomass could be interpreted not as undesirable material but, instead, as an unutilized feedstock/resource to be incorporated, e.g., in the waste-to-fuel cycle. Moreover, the rising demand for different seaweed products (food, pharmaceuticals, cosmetics, etc.) is expected to reflect in growing macroalgae cultivation (in this perspective even sea eutrophication could be interpreted as a benefit!) and in subsequent availability of biowaste for energy purposes [1]. 
When choosing routes to transfer macroalgae biowaste into combustible fuel, many authors [3; 4; 6] propose anaerobic digestion to be a particularly promising method for successful algae biomaterial treatment (other biofuel related transformation ways for seaweeds are identified in, e.g. [3; 7]). Concretely, high proportion of carbohydrates and low fraction of lignocellulosic compounds in macroalgae bodies $[1 ; 8]$ favour microbial digestion/decomposition and, accordingly, conversion of algae biomass to methane-rich biogas. Set of interplaying factors (e.g., temperature, $\mathrm{pH}$, humidity, substrat particle size, algae species-specific physiology, microbial communities' interactions, etc.) is influencing both macroalgae resources development and the waste substrate biodegradation process and, accordingly, affects the yield of biogas [1]; moreover, the biogas output could depend more on the background conditions than the material chosen (example see [11]).

Present research chooses microbial additions/pretreatment dimension within the spectrum of these factors since co-digestion/co-fermentation of different substances could represent itself as particularly important agent to enhance biodegradation of algal substrate. Accordingly, the aim of the recent pilotresearch is the following: to assess the biogas output from seaweed Furcellaria substrate enhanced/treated by a selected inoculum, namely, winemaking waste. Winemaking waste management practice recently includes development of different commercial products with converting waste into biofuel among other projects $[9 ; 10]$. Since the winemaking industry in Latvia produces considerable amount of waste (roughly estimating, about 20 tons per year) a promising project could be utilizing this biowaste for macroalgae substrate enhancement (since winemaking is not a large scale industry in Latvia, pomace should not be used as a feedstock substrate itself but just as inoculum to seaweed detritus); certain relevant preliminary research has been already carried out in Latvia [11].

As regards the definite seaweed chosen for the research: Furcellaria lumbricalis (Hudson) J.V.Lamouroux 1813 (red algae Rhodophyta) has been selected since this species is represented in the Western coast of Latvia by particularly abundant populations (see, e.g. [7]) and its biowaste is washed ashore there in considerable amounts. Furcellaria detritus was collected and supplemented with the winemaking waste (obtained from homemade wine producer) as an inoculum in order to carry out relevant biogas producing experiments.

\section{Materials and methods}

The experiment has been set up using a biogas anaerobic digestion installation (see Fig.1). Feedstock (i.e. processed seaweed with or without inoculum) has been placed in a sealed 301 capacity container, equipped with electric heating and a thermostat (accuracy $\pm 0.5^{\circ} \mathrm{C}$ ). Qianwei Kromschroder G-1.6 brand electronic gas flow meter (accuracy $\pm 1 \%$ ) was used to measure the exhaust gas volume. A gas analyzer consisting of a methane $\mathrm{CH}_{4}$ sensor MQ-4 and data-processing equipment based on a microcontroller with a data retention function was used to measure the methane composition (accuracy $\pm 2 \%$ ). A gas storage bin is added to the gas outlet pipeline, which, if necessary, can be closed with a tap. A back pressure valve/siphon has been added to the installation as well.

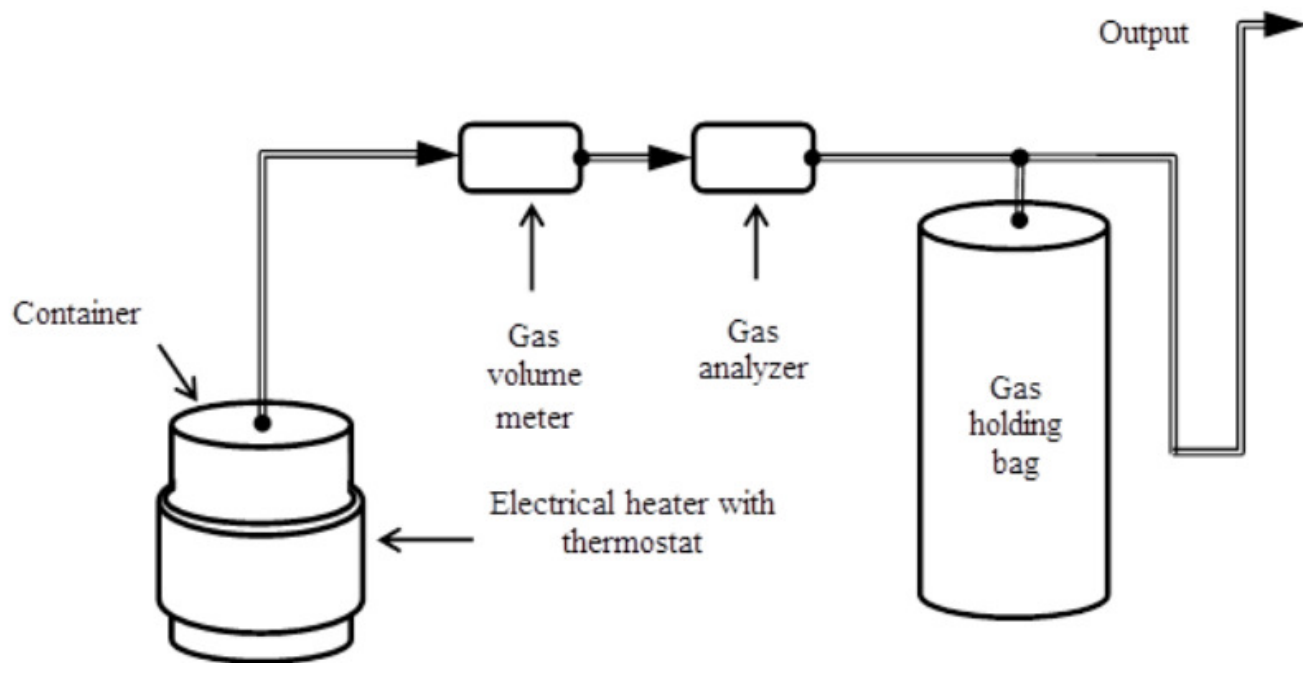

Fig. 1. Biogas digestion installation 


\section{Experiment 1}

In the first experiment fermentation of processed seaweeds without inoculum was performed. Algae were washed in fresh water, boiled for about 2 hours to separate the agar and then placed in the reactor. Total algae mass at $85-90 \%$ moisture was $12.5 \mathrm{~kg}$. The contents of the container were mixed periodically (3-4 times daily). At $70^{\circ} \mathrm{C}$ for the first 6 days, the temperature was then reduced to $50{ }^{\circ} \mathrm{C}$ in the following days. The comparative graph shows (see Figure 2, thick line) that release of the gas began late, after 19-20 days, and the amount of gas released was relatively small. Methane $\mathrm{CH}_{4}$ content in biogas was also small (see Figure 3, thick line). Biogas release stopped on day 37.

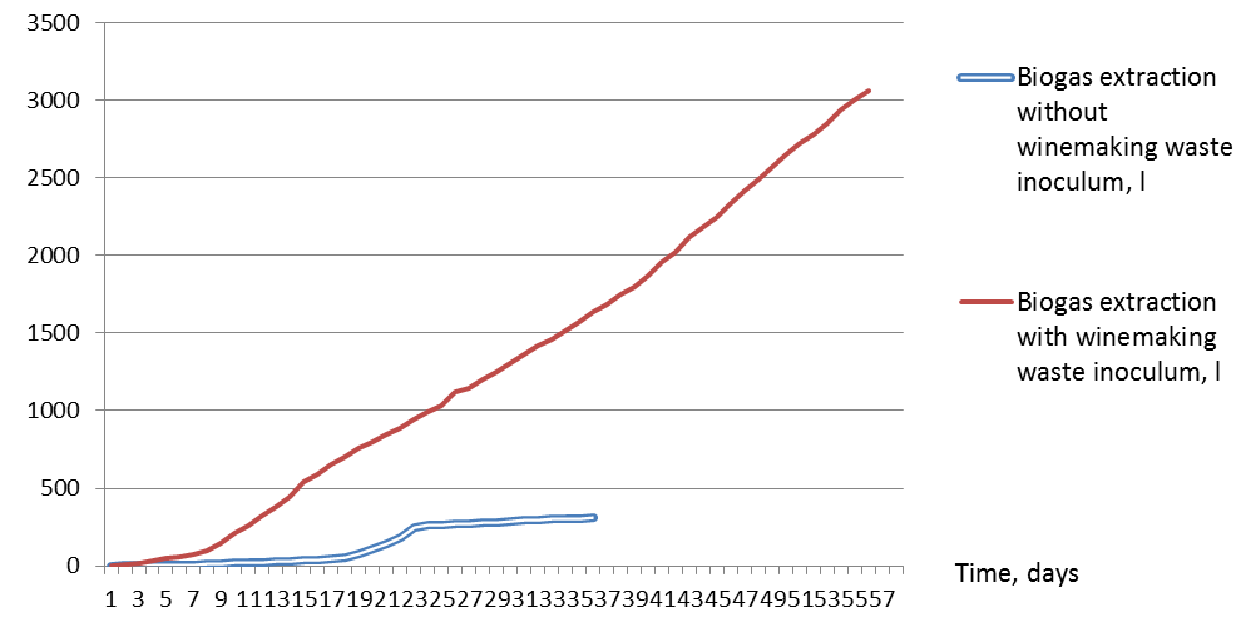

Fig. 2. Biogas output with and without winemaking waste inoculum

\section{Experiment 2}

In the second experiment, seaweeds and winemaking waste (co-fermentation system) were used. $12 \mathrm{~kg}$ of processed seaweed (processed - i.e. rinsed in fresh water, boiled for about 2 hours to separate from agar) were placed in the container and waste of different berry wines (black currant, apple) was added. Winemaking waste was added in 4 portions: day $3-1.1 \mathrm{~kg}$, day $10-0.8 \mathrm{~kg}$, day $17-0.8 \mathrm{~kg}$ and day $40-1.0 \mathrm{~kg}$. After adding, the contents of the container were mixed up. A constant temperature of $50^{\circ} \mathrm{C}$ was maintained throughout the experiment.

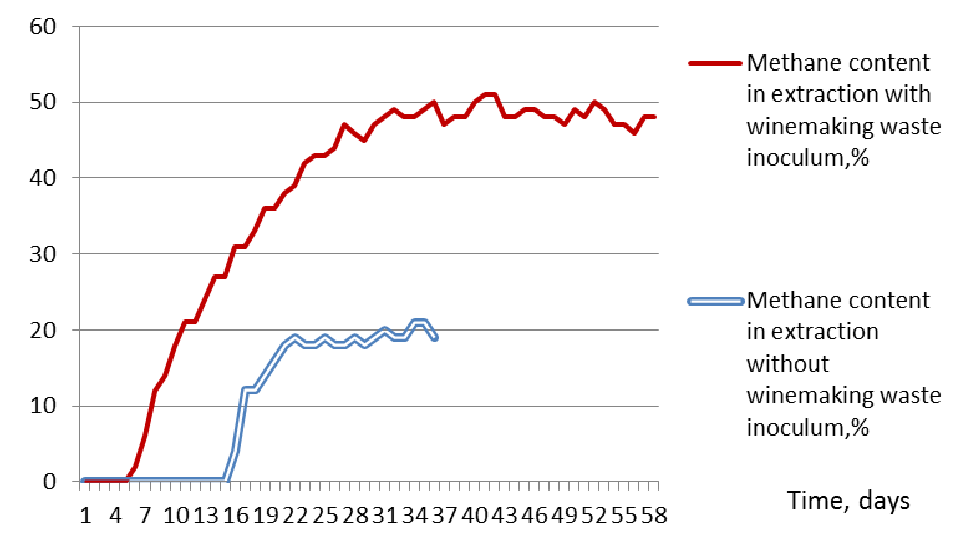

Fig. 3. Methane content in biogas with and without winemaking waste inoculum

\section{Results and discussion}

Both experiments yielded a very different amount of biogas and ratio of the methane content demonstrating thus winemaking residues inoculum beneficial influence on anaerobic digestion of feedstock (see Fig. 2 and Fig. 3)

Accordingly, the experiment performed supports the idea that the co-fermentation system made by Furcellaria seaweed detritus and winemaking waste represents itself as a promising project for biogas production. Nevertheless, there is the following limiting environmental and social aspect: the 
seasonal nature of the availability of seaweeds detritus and winemaking waste; at least, it is important that the time of seaweeds harvesting and wine production coincides - it is the end of summer and autumn.

Still, since this has been just a preliminary/pilot study, more detailed relevant research must be implemented. Further research should be focused on winemaking waste ratio impact on biogas yield, on comparisons of different inocula (winemaking waste, soured milk, cattle manure and like) decomposing efficiency as well as on the environmental factors (e.g. $\mathrm{pH}$, temperature changes, substrate shredding), which considerably influence anaerobic digestion. In particular, anaerobic digestion experiments should now be repeated for temperature of $38^{\circ} \mathrm{C}$, which has been recognized as an optimal one for biomaterial anaerobic decomposition (see, e.g. [3]).

\section{Conclusions}

1. According to the pilot studies, the seaweed Furcellaria (substrate) and winemaking waste (inoculum) co-fermentation system offers a promising feedstock for biogas (biomethane) production.

2. Preliminary experiments based further research is necessary to justify anaerobic digestion related efficiency of the Furcellaria-winemaking waste co-fermentation system and to clarify the relevant functional role of the environmental factors.

3. Particular emphasis should be put on experiments with unprocessed feedstock (unwashed seaweed detritus with natural additions like seawater salts and dead small animals - barnacles, gammarids, bivalves, etc.).

4. Besides economic gains, Furcellaria anaerobic digestion projects would facilitate the Baltic Sea coastal environment quality improvement.

\section{References}

[1] Barbot Y.N., Al-Ghaili H., Benz R. A review on the valorization of macroalgal wastes for biomethane production. Marine Drugs, vol. 14, 120, 2016, pp. 1-27.

[2] Spellman F.R. Environmental impacts of renewable energy, London, NY:CRC Press, 2014,478 p.

[3] Ramirez C.H.V. Biogas production from seaweed biomass: a biorefinery approach (Ph.D. thesis). Sligo: Institute of Technology, 2015. 203 p.

[4] Pastare L., Romagnoli F., Lauka D. etc. Sustainable use of macro-algae for biogas production in Latvian conditions: a preliminary study through an integrated MCA and LCA approach. Environmental and Climate Technologies, vol. 13, 2014, pp. 44-56.

[5] Vanegas C.H., Bartlett J. Green energy from marine algae: biogas prod. and comp. from the anaerobic digestion of Irish seaweed species. Env. Technology, Vol. 34, 2013, pp. 2277-2283.

[6] Uggetti E., Passos F., Solé M. etc. Biogas from algae via anaerobic digestion. Bux F., Chisti Y. (eds) Algae Biotechnology: Green Energy and Technology. Berlin: Springer, 2016, pp. 195-216.

[7] Balina K., Romagnoli F., Pastare L. etc. Use of macroalgae for bioenergy production in Latvia: review on potential availability of marine coastline species. Energy Procedia, vol. 113, 2017, pp. 403-410.

[8] Jiang R., Ingle K.N., Golberg A. Macroalgae (seaweed) for liquid transportation biofuel production: what is next? Algal Research, Vol. 14, 2016, pp. 48-57.

[9] Devesa-Rey R., Vecino X., Varela-Alende J.L. etc. Valorization of winery waste vs. the costs of not recycling. Waste Management, vol. 31, 11, 2011, pp. 2327-2335.

[10]Zacharof M-P. Grape winery waste as feedstock for bioconversions: applying the biorefinery concept. Waste and Biomass Valorization, vol. 8, 4, 2017, pp. 1011-1025.

[11] Jasko J., Skripsts E., Dubrovskis V. Biogas production of winemaking waste in anaerobic fermentation process. Proceedings of International conference "Engineering for rural development”, May 24-25, 2012, Jelgava, Latvia, pp. 576-579. 